\title{
A importância da enfermagem forense para enfermeiros que atuam nas unidades de emergência
}

\author{
The importance of forensic nursing for nurses working in emergency units
}
La importancia de la enfermería forense para las enfermeras que trabajan en unidades de emergência

Júlio César Rabêlo Alves ${ }^{1 *}$, Maurício José Jesus da Paz.

\begin{abstract}
RESUMO
Objetivo: Relatar a importância da inserção dos conhecimentos da enfermagem forense nos serviços e unidades de emergência. Metodologia: Trata-se de uma revisão integrativa de literatura com abordagem descritiva, utilizando bases científicas da SciELO e BVS de 2013 a 2018, postada na íntegra e na língua portuguesa do Brasil e de Portugal. Resultados e Discussões: Foram encontradas referências que relatam que os elevados índices de violências propiciaram o surgimento da enfermagem forense, associando a importância de sua inserção nos serviços e unidades de emergência porque são a porta de entrada para esses tipos de atendimentos. O enfermeiro emergencista, quase sempre, é o primeiro a prestar assistência aos envolvidos nos casos de criminalidade e, por isso, precisa ter uma instrução para iniciar as intervenções forenses. Tais profissionais atendem com frequência envolvidos em violências, mas sem ter noção de um protocolo que trace a sua ação, necessitando de uma conduta que demande um saber agir nessas situações. Considerações finais: A Enfermagem Forense tem uma atuação diversa, é inovadora e torna-se fundamental com o aumento das ocorrências de violências no mundo atual. Portanto, é fundamental instituíla nas emergências, dispondo de programas de especializações profissionais para a execução das suas funções.
\end{abstract}

Palavras-chave: Enfermagem Forense, Enfermagem em Emergência, Ciências Forenses.

\begin{abstract}
Objective: To report the importance of forensic nursing knowledge insertion in emergency services and units. Methodology: This is an integrative literature review with a descriptive approach, using scientific bases from SciELO and VHL from 2013 to 2018, posted in full and in the Portuguese language of Brazil and Portugal. Results and Discussion: References were found that the high rates of violence led to the emergence of forensic nursing, associating the importance of its insertion in services and emergency units because they are the gateway to these types of care. The emergency nurse is almost always the first to provide assistance to those involved in crime cases and therefore needs to be educated to initiate forensic interventions. These professionals frequently attend to violence, but without having a notion of a protocol that will trace their action, requiring a conduct that demands a knowledge to act in these situations. Final considerations: Forensic Nursing has a diverse performance, is innovative and becomes fundamental with the increasing occurrence of violence in the current world. Therefore, it is essential to institute it in emergencies, with programs of professional specialization for the performance of their duties.
\end{abstract}

Key words: Forensic Nursing, Emergency Nursing, Forensic Sciences.

${ }^{1}$ Centro Universitário Jorge Amado - UniJorge, Salvador - Bahia - Brasil. *E-mail: papito.julio@hotmail.com SUBMETIDO EM: 6/2019 ACEITO EM: 7/2019 PUBLICADO EM: 10/2019 


\section{RESUMEN}

Objetivo: Informar sobre la importancia de la inserción del conocimiento de enfermería forense en los servicios y unidades de emergencia. Metodología: Esta es una revisión de literatura integradora con un enfoque descriptivo, utilizando bases científicas de SciELO y VHL de 2013 a 2018, publicada en su totalidad y en el idioma portugués de Brasil y Portugal. Resultados y discusiones: Se encontraron referencias que informan que los altos niveles de violencia condujeron al surgimiento de la enfermería forense, asociando la importancia de su inserción en servicios y unidades de emergencia porque son la puerta de entrada a este tipo de atención. La enfermera de emergencia es casi siempre la primera en brindar asistencia a las personas involucradas en casos de delitos y, por lo tanto, debe ser educada para iniciar intervenciones forenses. Dichos profesionales a menudo asisten involucrados en la violencia, pero sin tener la noción de un protocolo que rastrea su acción, que requiere una conducta que exige conocimiento para actuar en estas situaciones. Consideraciones finales: la enfermería forense tiene un desempeño diverso, es innovador y se vuelve fundamental con la creciente incidencia de la violencia en el mundo actual. Por lo tanto, es esencial instituirlo en emergencias, con programas de especialización profesional para el desempeño de sus funciones.

Palabras clave: Enfermería Forense, Enfermería de Emergencia, Ciencias Forenses.

\section{INTRODUÇÃO}

A criminalidade é um ato violento que, historicamente, sempre fez parte da sociedade desde a ancestralidade. Mudaram-se os tempos, os motivos e suas notificações cresceram cada vez mais, tornandose, atualmente, um grande problema social. Com o surgimento da criminalidade nascem as ciências forenses, como um conjunto de conhecimentos científicos e técnicos para desvendar os atos criminosos, tentando compreender e explicar o comportamento criminal e da violência humana. Os berços da ciência forense datam desde o período do Antigo Egito, na investigação dos crimes, até a sua sentença final (GOMES CIA, 2016). Hoje, com os adventos tecnológicos, as ciências forenses contam com o auxílio de instrumentos e técnicas, como as interpretações das impressões digitais e das manchas de sangue que facilitam esse processo de investigação.

Diante desta realidade, o Anuário Brasileiro de Segurança Pública (2018) analisa dados de registros policiais sobre a criminalidade desde $\mathrm{o}$ ano de 2007, e no seu último levantamento demonstrou que 175 mortes por dia decorrem de violências intencionais no Brasil. Sendo que a maior incidência relatada foi por homicídio doloso, quando há intenção de matar. Registra-se ainda o crescente casos de estupros e feminicídios, que devido a atuação dos peritos forenses puderam ser notificadas.

É nesse cenário de criminalidade que surge a Enfermagem Forense, quando enfermeiras norteamericanas se dedicavam aos exames de perícia em vítimas de abuso sexual e estupro. Mas, segundo Gomes A (2014), somente em 1986 a referida especialidade é apresentada por Virgínia Lynch e, em 1991 é reconhecida como uma ciência forense, passando a ser um importante elo entre os estudos forenses e os cuidados em saúde.

Os crimes demandam de uma atuação imediata do enfermeiro emergencista, que quase sempre é o primeiro a prestar assistência, na manutenção da vida. Porém, apesar desta vital prioridade é também importante a preservação dos vestígios (biológicos e não biológicos) encontrados no corpo da vítima/agressor ou no local do evento, que mais tarde poderão ser alvo de prova pericial em Tribunal (GOMES CIA, 2016). Ao mesmo tempo em que conforme a Portaria $n^{\circ}$ 204/2016 do MINISTÉRIO DA SAÚDE, todas as situações que abrangem vítimas de violência precisam ser notificadas. Logo, o enfermeiro forense na emergência auxiliaria a justiça com a obtenção de provas obtidas no local do crime.

Coelho MAA (2013) assegura que é nesse contexto que se fundamenta a importância da formação de enfermeiros com conhecimento, técnicas e habilidades forenses nos serviços de emergência. Capazes de colher e preservar os vestígios demandados de um crime, já que são frágeis e facilmente deterioráveis, 
podendo ser alterados ou perdidos durante a assistência de enfermagem e, em caso disso acontecer, pouco poderá ser feito para recuperá-lo.

Então, como os serviços de urgência e emergência são a porta de entrada para a saúde, principalmente nos atendimentos de casos de criminalidade, a relação entre as ciências forenses com a enfermagem, nesse cenário de atendimento, torna-se cada vez mais importante. Os estudos de Gomes CIA (2016) apontam que a enfermagem forense pode ainda atuar em tribunais de justiça e desenvolver ações de educação preventiva para indivíduos com comportamento de risco, na detecção dos sinais de violência, e não só exercendo medidas terapêuticas, mas também de precaução. Essa atuação profissional já é realidade em países como, por exemplo, os Estados Unidos e Portugal, sendo uma necessidade natural nas emergências.

Entretanto, no Brasil a enfermagem forense ainda é uma teoria recente e, por isso, é pouco conhecida. Somente sendo inserida na lista de especialidades do Enfermeiro no ano de 2011 e reconhecida como atuação profissional em 2017, pelo Conselho Federal de Enfermagem (COFEN) na Resolução 556.

Justificando assim o limitado campo de sua execução nas emergências, embora os enfermeiros dessa área continuem atuando principalmente com vítimas de violência. Desta forma, o presente estudo tem como objetivo relatar a importância da inserção dos conhecimentos da enfermagem forense nos serviços e unidades de emergência.

\section{MÉTODOS}

Trata-se de uma revisão integrativa da literatura com abordagem descritiva. As plataformas de busca utilizadas foram a Scientific Electronic Library Online (SciELO) e a Biblioteca Virtual de Saúde (BVS), encontrando bases científicas para referenciais bibliográficos e filtrando-as de acordo com a temática proposta para compor a presente pesquisa. Na realização desta foi definido os descritores: "Enfermagem Forense", "Enfermagem em Emergência" e "Ciências Forenses", de acordo com a classificação dos Descritores em Ciências de Saúde (DESC).

Para elucidar o conhecimento, foram utilizadas dissertações de mestrados, artigos, livros e materiais da página da Associação Brasileira de Enfermagem Forense (ABEFORENSE) e do COFEN. Incluindo os que estavam disponíveis na íntegra e gratuitamente na língua portuguesa do Brasil e de Portugal, entre 2013 e 2018 por entender que esse período compreende as notícias mais recentes. A seleção dos conteúdos baseouse nos que relacionassem as ciências forenses com a atuação dos enfermeiros emergencistas, nesse novo contexto profissional.

Considerando a pouca quantidade de conteúdo sobre este assunto no Brasil, justifica-se o uso limitado nas referências. Assim, os critérios de inclusão e exclusão baseou-se na triagem por título, ano, idioma, resumo e leitura na íntegra, de acordo com a temática e metodologia proposta.

\section{RESULTADOS E DISCUSSÕES}

Foram encontradas referências que relatam que os elevados índices de violências propiciaram o surgimento da enfermagem forense, associando a importância de sua inserção nos serviços e unidades de emergência porque são a porta de entrada para esses tipos de atendimentos. Sob o ponto de vista de Gomes CIA (2016), a incorporação das ciências forenses no campo da enfermagem tem a capacidade de propor mudanças e melhorias nos cuidados prestados aos envolvidos em crimes, desenvolvendo competência para esse profissional. Esse tipo de conhecimento nas emergências tornou-se imprescindível, já que o enfermeiro emergencista, na maioria das vezes, estabelece o primeiro contato com as pessoas que recorrem aos serviços de saúde, sendo exposto aos cenários de suspeitas de violências. Podendo então, iniciar as intervenções forenses.

Segundo Coelho MAA (2013), o preparo dos enfermeiros forenses na emergência passa pela aptidão em estabelecer uma relação de confiança com os envolvidos na ação criminal, facilitando a anamnese, o exame físico e consequentemente sendo importante para recolher informações pertinentes na cooperação da 
investigação criminal. Estes que aprendem a não deixar nenhum vestígio despercebido ou ignorado, que pode ser um indício da violência, como, por exemplo, na verificação de feridas, arranhões, mordidas, hematomas e presença de materiais biológicos. Evidenciando que em algumas situações, não perdurarão por muito tempo e, por isso, necessitam de registro imediato.

Então, conforme o Regulamento das Competências Técnicas da Enfermagem Forense (ABEFORENSE, 2015) e do Anexo da Resolução 556 (COFEN, 2017), compete ao enfermeiro emergencista forense: identificar cenários de violências; garantir a segurança da vítima, com ou sem vida; realizar exame físico minucioso, identificando lesões e classificando-as em intencionais ou não intencionais; coletar e preservar os vestígios; medir as lesões e determinar sua forma, podendo estabelecer uma relação da violência com o tipo de objeto utilizado, através da interpretação do mecanismo de força (cinética do crime); realizar registros fotográficos; e documentar os nomes das pessoas que estiverem em contato com a vítima durante o seu tratamento e/ou seu deslocamento até a unidade hospitalar.

Além disso, compete detalhar os procedimentos terapêuticos realizados; descrever os materiais recolhidos, colocando a data e hora desta ação (cadeia de custódia), garantindo sua legalidade e confidencialidade; armazenar roupas em sacos de papel e nunca em sacolas plásticas, pois estas permitem a passagem de luz que cria um ambiente úmido e favorece a multiplicação de bactérias; desenvolver técnicas de entrevista com os envolvidos; e pode, até mesmo, servir como testemunha em tribunais, além de todo o contexto de uma investigação criminal. Todas essas funções têm o propósito da melhor análise do delito, e para atingir esse objetivo o pensamento tem que consistir nas ações que irão refletir no futuro, focando não só no processo saúde-doença, mas também nas evidências da prática de violência.

Tomando como base Gomes CIA (2016), diz que os vestígios são os traços essenciais para o sucesso de uma investigação criminal, em busca do descobrimento da verdade, tornando uma prova decisiva para indicar a culpa ou inocência de um indivíduo. Então, o enfermeiro emergencista com o conhecimento forense atua já no local do crime, recolhendo, preservando e evitando a destruição e contaminação desses traços. Assim, a enfermagem forense torna-se uma necessidade fundamental nesse contexto, mas sua atuação profissional ainda é restrita no Brasil.

Desta forma, é importante a formação de enfermeiros com conhecimentos forenses, tendo a capacidade de pensamento crítico e tomada de decisões para a sua prática nos serviços e unidades de emergência. $O$ tempo de serviço profissional, a existência de protocolos institucionais e a qualidade acadêmica indicam o nível de conhecimento e execução dessa ciência. Torna-se crucial, então, o desenvolvimento intelectual e de habilidades do enfermeiro emergencista para a prática forense, na prestação dos cuidados iniciais e em todo contexto da investigação criminal.

Por fim, segundo Gomes A (2014), ser enfermeiro forense é cuidar bem, sem olhar a quem, para que se faça justiça. Favorecendo então, o saber de não criar um juízo de valor entre a vítima e o agressor, tendo uma interpretação objetiva no cenário do crime. Sendo esse o legado desta nova atividade profissional, com o propósito de favorecer o julgamento correto nos tribunais e com a perspectiva de diminuir os dados crescentes de violências.

\section{CONSIDERAÇÕES FINAIS}

A Enfermagem Forense tem uma atuação diversa, é inovadora e torna-se fundamental com o aumento das ocorrências de violências no mundo atual. Portanto, os enfermeiros emergencistas demandam de uma formação acadêmica complementar, treinamentos e/ou especializações que dialoguem sobre as ciências forenses. Pois, eles atendem com frequência vítimas de agressões sem ter noção de um protocolo que trace a sua ação, necessitando de uma conduta que demande saber agir nos cuidados em saúde aos envolvidos nos cenários de violências. Por isso, é essencial instituí-la como uma especialidade imprescindível nas unidades e serviços de emergência, estabelecendo uma relação entre o sistema de saúde e o judicial. 


\section{REFERÊNCIAS}

1. ABEFORENSE. Regulamento das Competências Técnicas da Enfermagem Forense, maio, 2015. Disponível em: http://www.abeforense.org.br/wp-content/uploads/2016/06/Compet\%C3\%AAncias-Tecnicas-da-EnfermagemForense.pdf. Acesso em: 27 ago. 2018.

2. ANUÁRIO BRASILEIRO DE SEGURANÇA PÚBLICA. São Paulo: Fórum Brasileiro de Segurança Pública, v. 12, 2018. ISSN 1983-7364.

3. BRASIL. COFEN. Anexo da Resolução n 581, de 11 de julho de 2018. Especialidades do Enfermeiro por área de abrangência. Disponível em: http://www.cofen.gov.br/wp-content/uploads/2018/07/Resolu\%C3\%A7\%C3\%A3o-5812018-ANEXO-ATUALIZA-PROCEDIMENTOS-PARA-REGISTRO-DE-P\%C3\%93SGRADUA\%C3\%87\%C3\%83O.pdf. Acesso em: 22 dez. 2018.

4. BRASIL. COFEN. Resolução no 556, de 23 de agosto de 2017. Anexo. Disponível em: http://www.cofen.gov.br/wpcontent/uploads/2017/08/ANEXO-RESOLU\%C3\%87\%C3\%83O-556-2017.pdf. Acesso em: 03 nov. 2018.

5. BRASIL. COFEN. Resolução oㅜ 556, de 23 de agosto de 2017. Regulamenta a atividade do Enfermeiro Forense no Brasil, e dá outras providências. Disponível em: http://www.cofen.gov.br/resolucao-cofen-no-05562017_54582.html. Acesso em: 27 out. 2018.

6. BRASIL. MINISTÉRIO DA SAÚDE. Portaria nํ 204, de 17 de fevereiro de 2016. Define a Lista Nacional de Notificação Compulsória de doenças, agravos e eventos de saúde pública nos serviços de saúde públicos e privados em todo o território nacional, nos termos do anexo, e dá outras providências. Disponível em: http://bvsms.saude.gov.br/bvs/saudelegis/gm/2016/prt0204_17_02_2016.html. Acesso em: 08 nov. 2018.

7. COELHO MAA. Impacto da formação em ciências forenses. Mestrado em Enfermagem Médico-Cirúrgica - $3^{\underline{a}}$ ed., Instituto Politécnico de Viseu - Portugal, out., 2013.

8. GOMES A. Enfermagem forense. 1를 ed. Lisboa: Lidel, 2014. 376 p. v. 1.

9. GOMES CIA. Preservação dos vestígios forenses: conhecimentos e práticas dos enfermeiros do serviço de urgência e/ou emergência. Dissertação de Mestrado em Medicina Legal e Ciências Forenses, Faculdade de Medicina da Universidade de Coimbra - Portugal, dez., 2016.

10. SANTOS MR, et al. Atuação e competência do enfermeiro forense na preservação de vestígios no serviço de urgência e emergência. In: CONGRESSO INTERNACIONAL DE ENFERMAGEM, v.1, n.1, maio 9-12, 2017. Anais eletrônicos... Aracaju - Sergipe: Universidade Tiradentes (UNIT), 2017.

11. SOUZA ACD, et al. O enfermeiro e a preservação de vestígios nos casos de violência sexual. In: CONGRESSO INTERNACIONAL DE ENFERMAGEM, v.1, n.1, maio 9-12, 2017. Anais eletrônicos... Aracaju - Sergipe: Universidade Tiradentes (UNIT), 2017. 